Check for updates

Cite this: RSC Adv., 2018, 8, 38701

Received 30th September 2018 Accepted 13th November 2018

DOI: $10.1039 / \mathrm{c} 8 \mathrm{ra0} 0132 \mathrm{~h}$

rsc.li/rsc-advances

\section{Weathering treatment coupled with nano-silica filling to promote the engineering property of municipal solid waste incinerator bottom ash}

\begin{abstract}
Qingna Kong, ${ }^{a}$ Jun Yao, (D) *a Qian Yang, ${ }^{b}$ Dongshen Shen ${ }^{c}$ and Yuyang Long ${ }^{c}$
A new approach including weathering treatment and nano-silica filling was employed to promote the engineering properties of municipal solid waste incinerator (MSWI) bottom ash. X-ray diffraction (XRD), scanning electron microscopy (SEM) and electron dispersive spectroscopy (EDS) was used to characterize the mineralogical and morphological changes due to the treatment. Changes of chemical stability, compressive strength and heavy metal leaching of MSWI bottom ash were also explored. After the weathering treatment, the content of organic matter decreased from $2.70 \%$ to $1.07 \%$, while the carbonates increased from $0.70 \%$ to $2.05 \%$. The nano-silica treatment filled the intrinsic and neo-formed micropores and coated the surface of MSWI bottom ash. Due to this process, the chemical stability was promoted. The compressive strength increased from 4.83 to $5.32 \mathrm{MPa}$. The leaching of $\mathrm{Cu}, \mathrm{Zn}, \mathrm{Pb}, \mathrm{Cr}$ and $\mathrm{Cd}$ sharply decreased from 250.05 to $89.97 \mathrm{mg} \mathrm{L}^{-1}, 1080.45$ to $173.14 \mathrm{mg} \mathrm{L}^{-1}, 1.25$ to $0.70 \mathrm{mg} \mathrm{L}^{-1}$, 72.58 to $12.96 \mathrm{mg} \mathrm{L}^{-1}$ and 0.94 to $0.30 \mathrm{mg} \mathrm{L}^{-1}$, respectively. The results suggested that the weathering treatment coupled with nano-silica filling could greatly promote the engineering properties of MSWI bottom ash, which is beneficial with respect to the reuse of MSWI bottom ash as the building material.
\end{abstract}

\section{Introduction}

Incineration is playing a more and more important role in municipal solid waste (MSW) treatment. For instance, in the past decade, the number of municipal solid waste incinerator (MSWI) facilities increased sharply from 47 to 220 in China, with the treatment capacity rising from 15000 to $219080 \mathrm{t} \mathrm{d}^{-1}$. $^{1}$ In 2016, a totally 61750000 ton of MSW was incinerated in China. In the incineration process, about $20 \%$ of the incinerated MSW was transformed to the solid residue, in which $80 \%$ is MSWI bottom ash. ${ }^{2}$ It is estimated that about 9880000 ton of MSWI bottom ash was produced per year, which has turned out to be a great waste stream.

MSWI bottom ash is classified as non-hazardous waste, which is strongly encouraged to be reused as a secondary construction material, such as road coffering and brick-making. ${ }^{3}$ The utilization of the MSWI bottom ash can save the natural resource like gravels and crushed rocks, and reduce the waste to be landfilled. ${ }^{4}$ However, several negative properties might inhibit its beneficial reuse. First, MSWI bottom ash has high porosity. The high porosity can affect the compressive strength of MSWI bottom ash. Compressive strength is the maximum stress that a material

${ }^{a}$ College of Life Science, Taizhou University, Linhai 317000, China. E-mail: 18806591228@163.com; Fax: +86 57688660336; Tel: +8657688660338

${ }^{b}$ Taizhou Environmental Protection Bureau, Taizhou 318000, China

${ }^{c}$ Zhejiang Provincial Key Laboratory of Solid Waste Treatment and Recycling, Zhejiang Gongshang University, Hangzhou 310018, China can withstand before failure in compression. It represents the stiffness of the material, that is, the ability to resist deformation. Secondly, MSWI bottom ash contains a certain content of organic matter. ${ }^{5}$ The organic matter will be degraded during the reuse process, which can form new pores in the MSWI bottom ash. Thirdly, MSWI bottom ash is a mineral assemblage, containing large amounts of soluble minerals and heavy metals. ${ }^{6,7}$ The leaching of minerals may interfere with the integrity of construction. The release of heavy metals is another concern with the respect of environmental protection. The engineering properties of MSWI bottom ash can be greatly promoted if these disadvantages can be overcome. Weathering is reported a simple and effective pretreatment for the MSWI bottom ash. ${ }^{8-11}$ During the weathering treatment, the amorphous and highly reactive minerals undergo carbonation and oxidation change and transform into stable assemblage. ${ }^{12}$ Besides, the residual organic matter can be premeditatedly degraded to avoid the forming of new pores during the reuse process. However, weathering has little effect on the porosity reduction. In contrast, it may increase the porosity due to the degradation of the residual organic matter. To promote the mechanical properties of the MSWI bottom ash, these micropore need to be covered. The introduction of nanoparticles may be the solution. The size of the nanoparticles is usually in the range of 5 to 100 nanometers, allowing its diffusion into the micropore. It has been applied in several areas including industry, package, high performance coating and electronics, where nanoparticles improve the mechanical properties of materials. ${ }^{13}$ Nano-silica is favorable filler due to the small 
size and self-aggregation to form three-dimensional network. As the silica is also the main composition of MSWI bottom ash, the nano-silica was thus selected as the filler in this study. To our best knowledge, although several technologies have been developed for the pretreatment of MSWI bottom ash, such as vitrification, water washing and immobilization with cement, few studies had focused on promoting the engineering properties of MSWI bottom ash by solving the above problems simultaneously. ${ }^{\mathbf{1 4 , 1 5}}$ However, this theme is of great importance as it can facilitate the reuse of MSWI bottom ash.

In this study, MSWI bottom ash was treated by weathering treatment and nano-silica filling. The weathering treatment was used to degrade the residual organic matter premeditatedly. The nano-silica treatment was used to fill the micropores and improve the surface characteristics. The mineralogical and morphological changes during the process were characterized by X-ray diffraction (XRD), scanning electron microscopy (SEM) and electron dispersive spectroscopy (EDS). The effect of the process on the chemical stability, compressive strength and heavy metal leaching was also discussed. We aim to provide a feasible way to promote the engineering properties of the MSWI bottom ash.

\section{Material and methods}

\subsection{MSWI bottom ash sampling}

Fresh MSWI bottom ash sample was taken from Weiming plant in Zhejiang province, East China. The plant was consisted of three parallel stoker incinerators with a MSW treatment capacity of $900 \mathrm{t} \mathrm{d}^{-1}$. The source MSW was collected from several residential area of Taizhou. The operating temperature of the incinerators was $900-1100{ }^{\circ} \mathrm{C}$, and the residence time of waste in the incinerator was about $50 \mathrm{~min}$. MSWI bottom ash had been through water quenching and magnetic separation before being sampled. The sampling period lasted for 5 days. Approximately $30 \mathrm{~kg}$ fresh MSWI bottom ash sample was taken daily from the plant. A totally $150 \mathrm{~kg}$ MSWI bottom ash sample was obtained. Then, MSWI bottom ash was mingled and homogenized. Subsequently, a probably $30 \mathrm{~kg}$ of the MSWI bottom ash was oven-dried and grounded into less than $154 \mu \mathrm{m}$ (100-mesh) with grinder for bulk composition analysis, while the remaining part was prepared for the weathering treatment.

\subsection{Weathering treatment}

MSWI bottom ash was treated by the accelerated weathering method reported in our previous researches. ${ }^{12,16}$ It was carried out in a lab-scale airtight column reactor where a continue air flow $\left(2.0 \mathrm{~m}^{3} \mathrm{~min}^{-1}\right)$ was blown by an external pumping apparatus. The diameter of the reactor was $50 \mathrm{~cm}$, and the height was $60 \mathrm{~cm}$. The accelerated weathering treatment lasted for 129 hours until the $\mathrm{pH}$ of the MSWI bottom ash kept relatively steady. The samples were taken from the different depths within the reactor at different time.

\subsection{Nano-silica surface modification}

Nano-silica was purchased from Yuanjiang chemical company, with the grain size of $30 \mathrm{~nm}$ and zeta potential of $-15.32 \mathrm{mV}$.
$1000 \mathrm{~mL}$ DI water and $100 \mathrm{~g}$ nano-silica were mixed with magnetic stirring plate for $30 \mathrm{~min}$. Then, $200 \mathrm{~g}$ weathered MSWI bottom ash was added into the mixture. The mixture was stirred for $30 \mathrm{~min}$ and refluxed at $60{ }^{\circ} \mathrm{C}$ for $24 \mathrm{~h}$. After cooling, the MSWI bottom ash was separated by centrifugation and heated at $80{ }^{\circ} \mathrm{C}$ for $24 \mathrm{~h}$ to remove the residual water.

\subsection{Leaching procedure}

Leaching experiments were conducted according to the standard leaching test procedures synthetic precipitation leaching procedure (SPLP), which was set to simulate heavy metal leaching behavior under the acid precipitation (USEPA, 1996). In the procedure, $5 \mathrm{~g}$ fresh, weathered and nano-silica treated MSWI bottom ash were added into $100 \mathrm{~mL}$ acid solution with a $\mathrm{pH}$ of 4.20 respectively (adjusted with $\mathrm{HNO}_{3}$ and $\mathrm{H}_{2} \mathrm{SO}_{4}$ with the volume ratio of $4: 6)$. Solutions were shaken for $20 \mathrm{~h}$ at $25{ }^{\circ} \mathrm{C}$. After being shaken, the solution was filtered through $0.45 \mu \mathrm{m}$ membrane filter. The resulting solutions were analyzed for $\mathrm{Cu}, \mathrm{Zn}, \mathrm{Pb}, \mathrm{Cr}$ and Cd by ICP-AES. The SPLP was conducted in triplicate.

\subsection{Analytical procedure}

The moisture content was determined by ASTM D2216. The $\mathrm{pH}$ was determined for the suspension after $24 \mathrm{~h}$ equilibration period with liquid-to-solid ratio of 5 . The LOI, including $\mathrm{LOI}_{600}$ ${ }^{\circ} \mathrm{C}$ and $\mathrm{LOI}_{950}{ }^{\circ} \mathrm{C}$ were determined by heating the bottom ash samples at $600{ }^{\circ} \mathrm{C}$ and $950{ }^{\circ} \mathrm{C}$ respectively, according to the Chinese standard GB7876-87. Respectively, the value of $\left(\mathrm{LOI}_{600}\right.$ ${ }^{\circ} \mathrm{C}-$ moisture content) indirectly reflected the organic matter content in MSWI bottom ash, while the value of $\left(\mathrm{LOI}_{950}{ }^{\circ} \mathrm{C}-\right.$ $\left.\mathrm{LOI}_{600}{ }^{\circ} \mathrm{C}\right)$ reflected the content of carbonate minerals. Measurements were conducted in triplicate.

Mineralogical investigations of the MSWI bottom ash samples were carried out by XRD. Morphological characteristics of the MSWI bottom ash samples were characterized by SEM by using a mode Quanta 200 FEG ESEM 1. The semi-quantities chemical analysis of the MSWI bottom ash samples were carried by EDS.

The chemical stability of the MSWI bottom ash sample was determined by the standard method of China (T 0314-2000), which was used to evaluate the mass loss under high the salinity circumstance. The compressive strength of the MSWI bottom ash sample was determined by the standard Proctor compaction test. In the test, MSWI bottom ash was subjected to a comprehensive load. The cylindrical specimens were $102 \mathrm{~mm}$ in diameter and $122.5 \mathrm{~mm}$ long, with a total volume of $1 \mathrm{~L}$. Loading is performed at a uniform rate $\left(1.0 \mathrm{~mm} \mathrm{~min}^{-1}\right)$. The stress-strain curve was obtained in the compression test. The maximum compressive strength is recorded as the maximum stress that MSWI bottom ash can withstand. Measurements were conducted in triplicate.

\section{Results and discussion}

\subsection{Variation of the physi-chemical properties during the weathering treatment}

3.1.1 pH. The initial $\mathrm{pH}$ of the equilibrated suspension of fresh MSWI bottom ash was 11.54 (Fig. 1), which was basically 


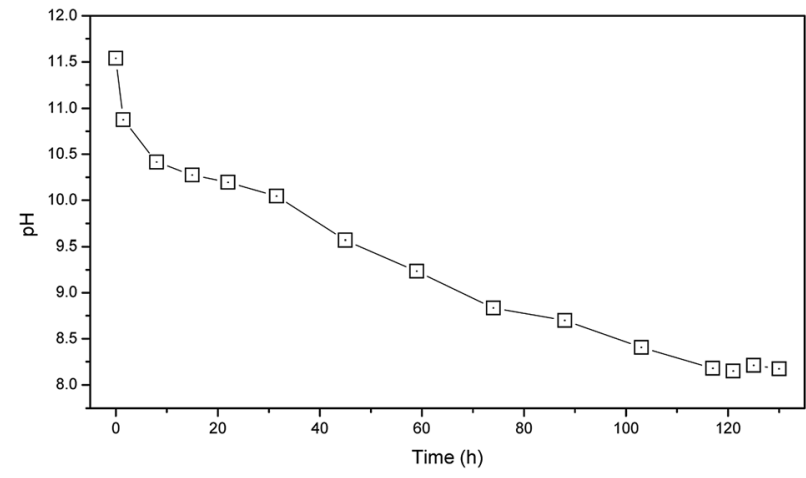

Fig. 1 Profile of $\mathrm{pH}$ evolution during weathering treatment.

in agreement with the previous researches. ${ }^{11,17}$ After the incineration, most of the alkali metals were presented as oxides in the MSWI bottom ash, which transformed into hydroxides after the quench treatment. The high $\mathrm{pH}$ was probably resulting from the dissolution of the hydroxides. Due to the weathering treatment, the mineralogical characteristics of MSWI bottom ash were changed. Especially, carbonation was thought to be the primary weathering reaction. The atmospheric $\mathrm{CO}_{2}$ reacted with the surface alkaline minerals and formed carbonates. This was confirmed by the XRD pattern of MSWI bottom ash, which showed the content of $\mathrm{CaCO}_{3}$ increased after the weathering treatment (Fig. 2). Therefore, the pH of MSWI bottom ash decreased with the progress of weathering (Fig. 1). After 117 hours, the pH of MSWI bottom ash decreased to 8.18. Since then, no further significant $\mathrm{pH}$ decrease was observed. Meima and Comans $^{11}$ had pointed out that the $\mathrm{pH}$ of completely carbonated MSWI bottom ash was mainly controlled by the equilibrium of $\mathrm{CaCO}_{3}$, which ranged from 8.0-8.5. This result was consistent with this study.

3.1.2 Content of carbonates. With the progress of weathering treatment, the value $\left(\mathrm{LOI}_{950}{ }^{\circ} \mathrm{C}-\mathrm{LOI}_{600}{ }^{\circ} \mathrm{C}\right)$ showed an increasing trend (Fig. 3), indicating the increase of carbonates
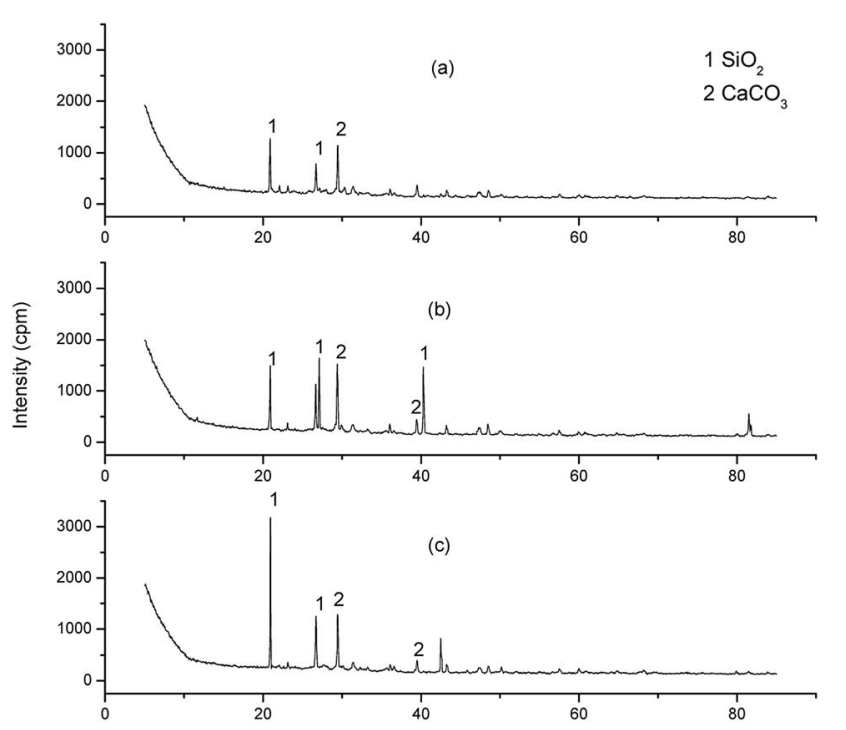

Fig. 2 XRD pattern of the MSWI bottom ash samples ((a) fresh sample; (b) weathered sample; (c) nano-silica treated sample).

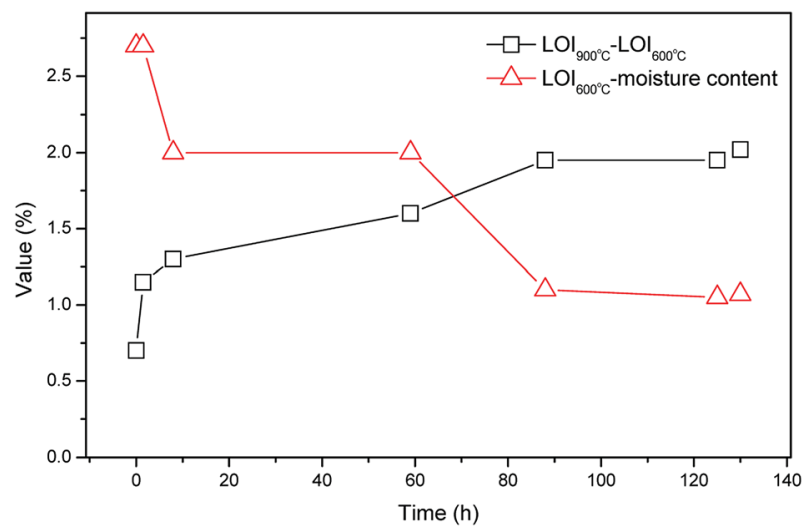

Fig. 3 Profile of evolution of $\mathrm{LOl}_{900}{ }^{\circ} \mathrm{C}$ and $\mathrm{LOI}_{600}{ }^{\circ} \mathrm{C}$ during weathering treatment.

in MSWI bottom ash. This result was in agreement with the XRD pattern of the MSWI bottom ash samples, in which the increase of $\mathrm{CaCO}_{3}$ was observed after the weathering treatment (Fig. 3). The variation of carbonates was also consistent with the evolution of $\mathrm{pH}$. At the first 8 hours, the carbonates increased sharply from $0.7 \%$ to $1.3 \%$, corresponding to the sharp decrease of $\mathrm{pH}$ from 11.54 to 10.41 . It could be attributed to the fast consumption of hydroxides by $\mathrm{CO}_{2}$. After 8 hours, the decrease of $\mathrm{pH}$ slowed down as the surface reactive hydroxides had been greatly reduced. Till the end of the study, the content of carbonates came to $2.05 \%$.

3.1.3 Content of organic matter. During the weathering treatment, the content of organic matter in MSWI bottom ash decreased from $2.70 \%$ to $1.07 \%$ (Fig. 3). Previous studies had shown that the weathering could decrease the organic matter by the oxidation and biodegradation, which was in agreement with this study. ${ }^{8,18}$ The oxidation or biodegradation of the organic matter could change the surface morphology of MSWI bottom ash. As shown in Fig. 4(b), new pores formed in the microsurface after the weathering treatment. The forming of new pores should also be expected if fresh MSWI bottom ash was reused as construction material, which could influence the intensity of construction in the long run. The premeditatedly consumption of organic matter by the weathering treatment could help to repair the pores and avoid the risk.

\subsection{Variation of the chemical stability}

The fresh MSWI bottom ash sample showed $13.8 \%$ of mass loss in the chemical stability test, which could be due to the leaching of the soluble minerals of MSWI bottom ash (Fig. 5). The mass loss ratio decreased to $9.0 \%$ after the MSWI bottom ash was weathering treated. It suggested that the weathering treatment could immobilize part of minerals in MSWI bottom ash. For example, the transformation of calcium hydroxide into calcium carbonate lowered the solubility of the mineral, which decreased the leaching of the mineral. Surprisingly, the nanosilica treated MSWI bottom ash showed an increase of the mass by $4.24 \%$. The increase of the mass was probably due to the reaction of $\mathrm{Ca}^{2+}$ with $\mathrm{SO}_{4}{ }^{2-}$ (used as a reagent in the chemical stability test), forming the insoluble $\mathrm{CaSO}_{4}$. Besides, 


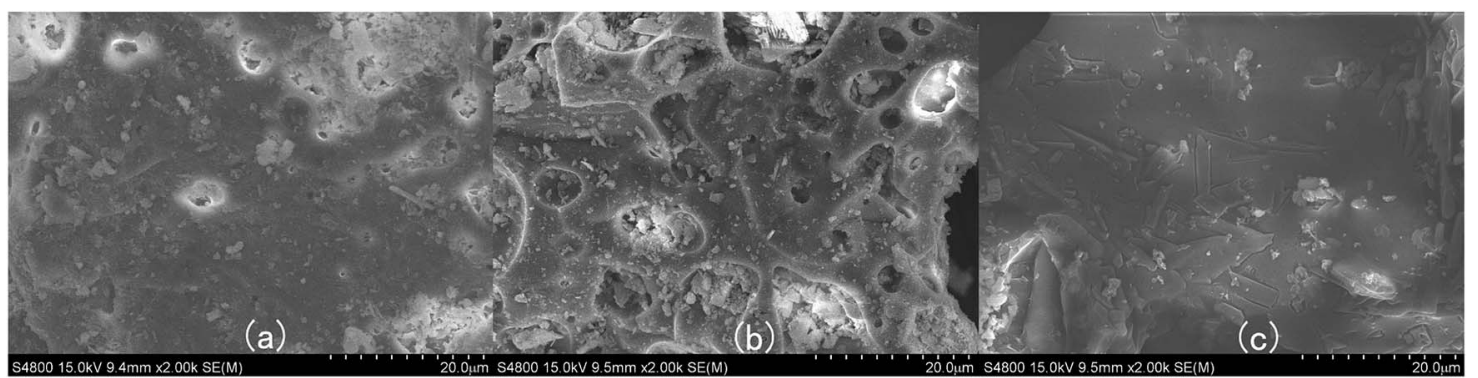

Fig. 4 SEM micrographs of MSWI bottom ash samples ((a) fresh sample; (b) weathered sample; (c) nano-silica treated sample).

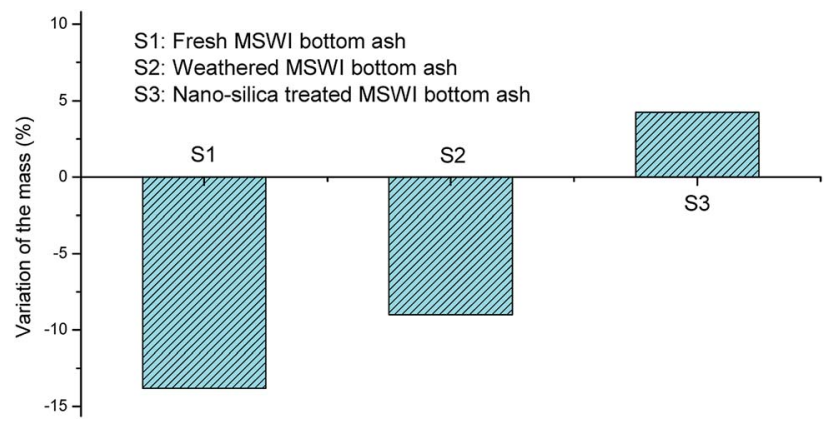

Fig. 5 Variation of the mass of MSWI bottom ash during the chemical stability test.

the surface modification by nano-silica also restricted the mineral leaching from MSWI bottom ash. As shown in Fig. 4(c), the surface of the MSWI bottom ash became smoother after the surface modification. It showed that not only the micropore was filled by the nano-silica, the surface of the MSWI bottom ash was coated by the dispersed nano-silica sheet (Fig. 4(c)). The surface coating was also evidenced by the EDS results, which showed that the content of $\mathrm{O}$ and $\mathrm{Si}$ increased after the nanosilica treatment, while the content of $\mathrm{Al}, \mathrm{Ca}, \mathrm{K}$ and $\mathrm{Na}$ decreased (Table 1). The surface coating prevented the contact of intrinsical minerals with the leachates. After the stability test, the residual solution was determined for the element concentration, which was shown in Table 2. Compared with the fresh MSWI bottom ash, the leaching of $\mathrm{Ca}$ and $\mathrm{Mg}$ was greatly mitigated after weathering treatment, while the leaching of $\mathrm{Na}$ and $\mathrm{K}$ was generally at the same level. For the nano-silica treated

Table 1 Element composition of MSWI bottom ash samples (\%)

\begin{tabular}{lllllll}
\hline & $\mathrm{O}$ & $\mathrm{Si}$ & $\mathrm{Al}$ & $\mathrm{Ca}$ & $\mathrm{K}$ & $\mathrm{Na}$ \\
\hline Weathered MSWI bottom ash & 44.7 & 11.7 & 7.6 & 8.9 & 3.9 & 4.2 \\
Nano-silica treated MSWI bottom ash & 47.2 & 21.0 & 6.3 & 3.7 & 1.7 & 2.4
\end{tabular}

Table 2 Element concentration in the solution of the chemical stability test $\left(\mathrm{mg} \mathrm{L}^{-1}\right)$

\begin{tabular}{lrrrr}
\hline & $\mathrm{Na}$ & $\mathrm{K}$ & $\mathrm{Ca}$ & $\mathrm{Mg}$ \\
\hline Fresh MSWI bottom ash & 21.22 & 16.45 & 90.77 & 24.35 \\
Weathered MSWI bottom ash & 20.36 & 17.11 & 36.43 & 13.44 \\
Nano-silica treated MSWI bottom ash & 8.76 & 9.77 & 14.53 & 5.44
\end{tabular}

MSWI bottom ash, the leaching of $\mathrm{Na}, \mathrm{K}$ and $\mathrm{Ca}$ was greatly reduced compared with the fresh and weathered MSWI bottom ash. This result verified the fact that weathering treatment could immobilize part of the minerals, while the nano-silica treatment could coat the surface of the MSWI bottom ash and further decrease the leaching of minerals.

\subsection{Variation of the compressive strength of MSWI bottom ash}

Weathering treatment slightly increased the compressive strength of MSWI bottom ash. The maximum compressive strength value of the weathered MSWI bottom ash was 4.97 $\mathrm{MPa}$, while the maximum compressive strength value of fresh MSWI bottom ash was 4.83 MPa (Fig. 6). Previous study has showed that the weathering treatment improve the mechanical response to load. ${ }^{18}$ The neo-formed phase was reported as a binder in MSWI bottom ash, resulting in the increase of the compressive strength. Although new pores were formed during the weathering treatment, as shown in the SEM micrographs (Fig. 4(b)), the increase of compressive strength seemed to be able to cover disadvantage of the neo-formed pores. After the nano-silica treatment, the maximum compressive strength of MSWI bottom ash further increased to 5.32 MPa. As shown in Fig. 4, pores were filled by the nanosilica, which improved the ability to spread the load of the MSWI bottom ash. This result suggested that the weathering treatment and nano-silica filling could improve the mechanical properties as building materials, which is beneficial for the reuse of the MSWI bottom ash.

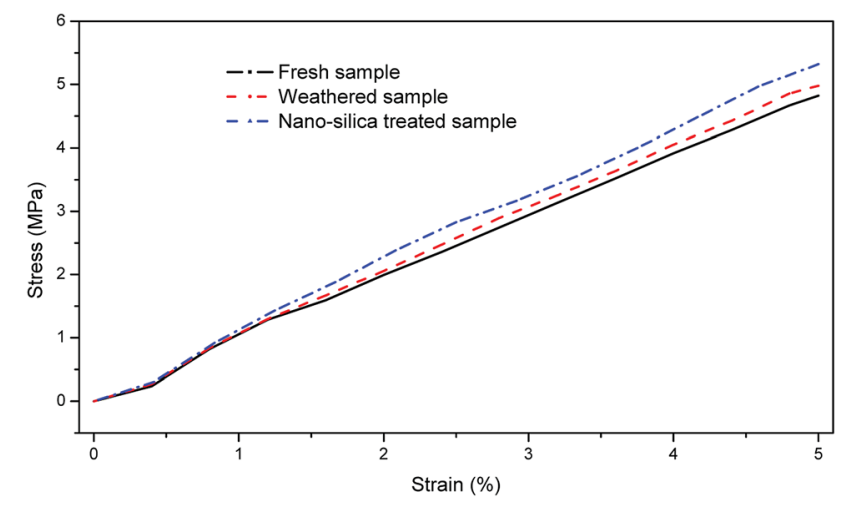

Fig. 6 Stress-strain curves of the MSWI bottom ash samples. 


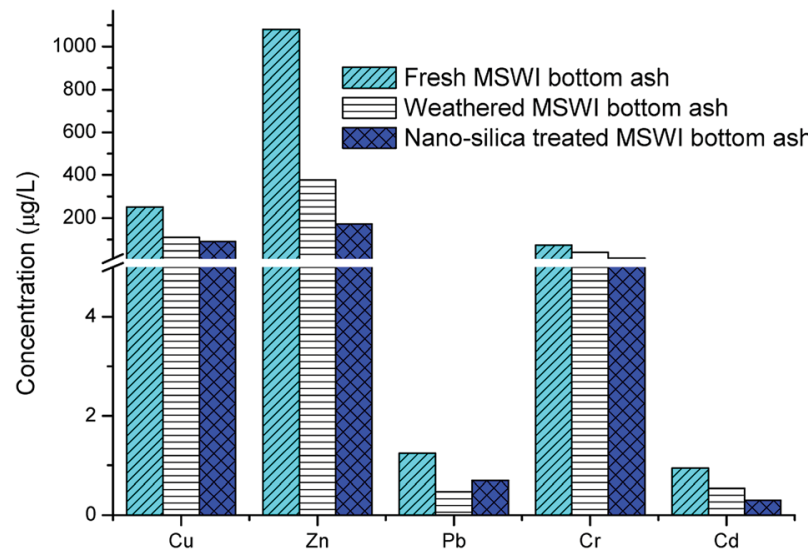

Fig. 7 Leaching behavior of heavy metal from the MSWI bottom ash samples.

\subsection{Variation of the metal leaching behavior}

Due to the weathering treatment, the leaching of $\mathrm{Cu}, \mathrm{Zn}, \mathrm{Pb}, \mathrm{Cr}$ and Cd decreased from 250.05, 1080.45, 1.25, 72.58 and $0.94 \mathrm{mg} \mathrm{L}{ }^{-1}$ to $111.17,376.79,0.47,39.97$ and $0.54 \mathrm{mg} \mathrm{L}^{-1}$, respectively (Fig. 7). The weathering treatment was thought to be able to change the speciation of the heavy metals. ${ }^{16}$ The neoformation of carbonates makes the heavy metal relatively stable in the SPLP test. Therefore, the release of the heavy metals was restricted. The nano-silica treatment filled the micropores and coated the surface of the MSWI bottom ash, which prevented the heavy metal from releasing (Fig. 4). Therefore, the leaching of $\mathrm{Cu}, \mathrm{Zn}, \mathrm{Cr}$ and $\mathrm{Cd}$ further decreased to 89.87, 173.14, 12.96 and $0.30 \mathrm{mg} \mathrm{L}^{-1}$, respectively. However, no further reduction of leaching was observed for $\mathrm{Pb}$. The leaching of $\mathrm{Pb}$ had been at a low level after the weathering treatment. The above results showed that the weathering treatment and nano-silica treatment process could significantly decrease the heavy metal leaching from MSWI bottom ash, which was beneficial for the reuse of MSWI bottom ash.

\section{Conclusions}

The process including weathering treatment and nano-silica filling could promote the engineering properties of municipal solid waste incinerator bottom ash. Weathering treatment could degrade the residual organic matter premeditatedly and change the mineralogy and morphology of MSWI bottom ash. The intrinsical and neo-formed pores due to the weathering treatment was then filled by the nano-silica. Besides, the nanosilica also coated the surface of MSWI bottom ash. As a result, the chemical stability of MSWI bottom ash increased. The compressive strength increased from 4.83 MPa to 5.32 MPa. The leaching of heavy metals, including $\mathrm{Cu}, \mathrm{Zn}, \mathrm{Pb}, \mathrm{Cr}$ and $\mathrm{Cd}$, decreased notably. It is believed that the reuse of MSWI bottom ash can be facilitated after being treated by the process of this study, which is important as MSWI bottom ash has turn out a great waste stream for a lot of cities.

\section{Conflicts of interest}

There are no conflicts to declare.

\section{Acknowledgements}

This work was financially supported by Natural Science Foundation of China with Grant No. 41601512 and 51578356, Public Technology Applied Research Fund of Zhejiang Province Science and Technology Department with Grant No. 2015C33234, and Natural Science Foundation of Zhejiang province with Grant No. Y19B070006.

\section{References}

1 National Bureau of Statistics of China, China Statistical Yearbook 2016, China Statistics Press, 2018.

2 J. M. Chimenos, M. Segarra, M. A. Fernändez and F. Espiell, J. Hazard. Mater., 1999, 64, 211-222.

3 Z. Youcai, S. Lijie and L. Guojian, J. Hazard. Mater., 2002, 95, 47-63.

4 J. R. Minane, F. Becquart, N. E. Abriak and C. Deboffe, Procedia Eng., 2017, 180, 1213-1220.

5 H. Ecke and M. Svensson, Waste Manag., 2008, 28, 13011309.

6 J. Yao, W. B. Li, Q. N. Kong, Y. Y. Wu, R. He and D. S. Shen, Fuel, 2010, 89, 616-622.

7 J. Yao, Q. N. Kong, H. Y. Zhu, Y. Y. Long and D. S. Shen, Chemosphere, 2015, 119, 267-272.

8 J. J. Dijkstra, A. Van Zomeren and J. C. L. Meeussen, Environ. Sci. Technol., 2006, 40, 4481-4487.

9 A. Polettini and R. Pomi, J. Hazard. Mater., 2004, 113, 209215.

10 S. Arickx, T. Van Gerven and C. Vandecasteele, J. Hazard. Mater., 2006, 137, 235-243.

11 J. A. Meima and R. N. J. Comans, Environ. Sci. Technol., 1997, 31, 1269-1276.

12 J. Yao, W. B. Li, Q. N. Kong, F. F. Xia and D. S. Shen, Fuel, 2012, 93, 99-104.

13 S. Beun, T. Glorieux, J. Devaux, J. Vreven and G. Leloup, Dent. Mater., 2007, 23, 51-59.

14 T. Sabbas, A. Polettini, R. Pomi, T. Astrup, O. Hjelmar, P. Mostbauer, G. Cappai, G. Magel, S. Salhofer, C. Speiser, $\mathrm{S}$. Heuss-Assbichler, R. Klein and P. Lechner, Waste Manag., 2003, 23, 61-88.

15 Q. Alam, M. V. A. Florea, K. Schollbach and H. J. H. Brouwers, Waste Manag., 2017, 67, 181-192.

16 J. Yao, W. B. Li, M. L. Tang, C. R. Fang, H. J. Feng and D. S. Shen, Chemosphere, 2010, 81, 571-576.

17 N. Um and J. W. Ahn, Process Saf. Environ. Prot., 2017, 111, 560-568.

18 J. M. Chimenos, M. A. Fernändez, L. Miralles, J. R. Rosell and A. N. Ezquerra, Environ. Sci. Technol., 2005, 39, 7725-7730. 